\title{
Real Costs Assessment of Solar-Hydrogen and Some Fossil Fuels by means of a Combustion Analysis
}

\author{
Giovanni Nicoletti, Roberto Bruno, Natale Arcuri, and Gerardo Nicoletti \\ Mechanical, Energetic and Management Engineering Department, University of Calabria, V. P. Bucci 46/C, Arcavacata, \\ 87036 Rende, Italy
}

Correspondence should be addressed to Giovanni Nicoletti; giovanni.nicoletti@unical.it

Received 6 October 2015; Revised 10 January 2016; Accepted 12 January 2016

Academic Editor: Kazunori Kuwana

Copyright (C) 2016 Giovanni Nicoletti et al. This is an open access article distributed under the Creative Commons Attribution License, which permits unrestricted use, distribution, and reproduction in any medium, provided the original work is properly cited.

\begin{abstract}
In order to compare solar-hydrogen and the most used fossil fuels, the evaluation of the "external" costs related to their use is required. These costs involve the environmental damage produced by the combustion reactions, the health problems caused by air pollution, the damage to land from fuel mining, and the environmental degradation linked to the global warming, the acid rains, and the water pollution. For each fuel, the global cost is determined as sum of the market price and of the correspondent external costs. In order to obtain a quantitative comparison, the quality of the different combustion reactions and the efficiency of the technologies employed in the specific application sector have to be considered adequately. At this purpose, an entropic index that considers the degree of irreversibility produced during the combustion process and the degradation of surroundings is introduced. Additionally, an environmental index that measures the pollutants released during the combustions is proposed. The combination of these indexes and the efficiency of the several technologies employed in four energy sectors have allowed the evaluation of the total costs, highlighting an economic scenario from which the real advantages concerning the exploitation of different energy carrier are determined.
\end{abstract}

\section{Introduction}

Nowadays energy saving applications and environmental protection could be achieved by the diffusion of newer and cleaner energy resources $[1,2]$. The gradual and continuous decrement of the reserves of fossil fuels and the problems of environmental pollution concerning their use determines an unpostponable transition to renewable energy [3]. The replacement of traditional fossil fuels is not difficult to assess also in the field of energy carriers, where hydrogen could represent a satisfactory solution in every sector of society. Moreover, it can be considered completely renewable if produced by electrolysis process of the water supplied by photovoltaic technologies [4-6].

The exploitation of the electrolytic hydrogen certainly will lead to significant reductions of the major air pollutants, in particular $\mathrm{CO}_{2}, \mathrm{SO}_{x}$, and particulate dusts, by improving the city livability and the environmental quality [7-9]. Additionally, solar-hydrogen diffusion could lead to the improvement of the photovoltaic and fuel cells technologies [10].

The diffusion of electrolytic hydrogen is currently impeded by technical and economic difficulties: some problems concerning storage and transportation have to be solved [11-14], besides the current market price of solar-hydrogen that makes it strongly unattractive [15].

In this paper, an economic comparison to compare solarhydrogen and some fossil fuels was carried out by means of the real economy approach. The competitiveness among the considered fuels is carried out by considering the total costs supported in a specific application sector. The total cost includes not only the market price of the fuel, but also the "external costs" related to the fuel exploitation. These external costs consider the environmental damage produced by the combustion reactions, the health problems caused by air pollution, the damage to land from fuel mining, and the 
environmental degradation linked to the global warming, the acid rains, and the water pollution. Usually, in energy sectors supplied by fossil fuels, the external costs are not considered, making the comparison with solar-hydrogen with no meaning [16].

The latter, in fact, reduces the harmful effects linked to the energy production with fossil fuels, allows the control of air pollution, and reduces some problems linked to water and soil utilization [1].

Several authors have investigated the hydrogen costs in different energy fields. Weinert et al. determined the costs required for the refueling of cars equipped with fuel cells technologies in Shangai [17]. Melaina, instead, investigated the costs concerning the hydrogen stations in US to evaluate the potential of hydrogen diffusion in the transportation sector [18]. Prince-Richard et al. have carried out a technoeconomic analysis in order to evaluate the costs concerning the hydrogen produced by electrolysis and destined to fuel cell vehicles [19]. Finally, Veziroğlu and Barbir proposed a particular approach to evaluate the real costs of different fuels, but by now these costs' result is outdated [20].

Unlike the latter document, in this paper a different approach to determine the total costs of solar-hydrogen and of traditional fossil fuels, based on thermodynamic evaluations, is introduced. These evaluations are required to consider the different effects linked to the combustion reactions; in function of the fuel exploitation, different quantity of released heat, emitted pollutants, and diverse effects on the external environment are produced. In order to take into account the mentioned aspects, in the economic analysis an appropriate weight factor that modifies the external costs and takes into account the aforementioned aspects is necessary. This weight factor is defined as product between two quality indexes: the first is an "entropic" index to measure the irreversibility degree of the combustion reaction and the quality of the same reaction and the second is an "environmental" index to determine the quantity of pollutants emitted in atmosphere. Additionally, since the quantity of fuel required in specific application sectors depends on the involved technology, the total cost is adjusted in function of the thermodynamic efficiency of the employed device. Thus, also considering different fuels with dissimilar thermodynamic and environmental properties, the employment of such parameters is normalized, allowing the obtainment of homogenous results. The comparison is carried out between solar-hydrogen and the currently diffuse fossil fuels in industrialized and emerging countries such as methane, coal, and gasoline/diesel.

The entropic impact index was investigated in thermodynamic open systems, whose state is defined by the values of enthalpy, Gibbs free energy, and chemical work [21, 22]. In function of the fuel properties, it measures the combustion quality and the environmental damage, since during the combustion process the lower the entropy production, the lower the impact on surroundings [23]. The environmental impact index, indeed, has been determined by considering the quantity of pollutants emitted and normalized in function of the thermal energy released during the combustion reaction. Finally, the product of the proposed indexes determines the global weight factor " $p$ ” required for the total cost evaluation. In order to assess the economic advantages concerning the exploitation of a specific fuel in opposition to another one, a reference fuel has to be recognized. For instance, if the benefits consequent to the solar-hydrogen exploitation have to be weighted against the methane, the latter will be classified as reference fuel. Therefore, the total costs of the investigated fuels can be evaluated by the relation [24]:

$$
S=\left\{C+E \cdot\left(\frac{p_{o}}{p}\right)\right\} \cdot\left(\frac{\eta_{o}}{\eta}\right),
$$

where $S$ is the total (or real) cost per unit of produced energy ( $€ / \mathrm{kWh}) ; C$ is the fuel price market per unit of energy delivered to the customer, including taxes (€/kWh); $E$ is the external cost consequent to the fuel use per unit of energy, expressed in current money $(€ / \mathrm{kWh}) ; \eta$ is the efficiency of the device supplied by a specific fuel in a specific application sector; $\eta_{o}$ is the efficiency of the technology supplied by the reference fuel in the same application sector; $p_{o}$ is the weight factor determined for the reference fuel.

Equation (1) allows the evaluation of the so-called "real costs," by moving the focus of the investigation to the end of the process of energy production and by extending the evaluation of the real costs by including the effects produced from the final use of the same fuels. The economic analyses have been carried out by considering the residential, the industrial, the power generation, and the transportation sectors as application areas.

\section{The Exploitation of Solar-Hydrogen as Energy Carrier}

A promising solution in the field of the clean fuels is represented by solar-hydrogen [1]. A hypothetical scheme of the complete cycle of energy production involving hydrogen as energy carrier starts from photovoltaic fields, and the possible exploitation in different energy sectors is shown in Figure 1. Every involved application provides liquid water, which could be reused to supply newly the hydrogen cycle, making the process more sustainable.

The technical difficulties to the exploitation of solarhydrogen concern the hydrogen storage systems and the structure of the hydrogen transportation, but the recent research campaign in these fields seems to show promising results $[12-14,25]$.

A large emitter of macropollutants $\left(\mathrm{CO}_{2}, \mathrm{NO}_{x}, \mathrm{CO}\right.$, $\mathrm{SO}_{x}$, and particulate) is represented by the sector of electric power generation that could be adequately supplied by hydrogen pipeline and can evolve towards the innovative use of new technologies as the fuel cells, realizing the tasks of high efficiency and contemporaneous production of thermal energy [26]. Alternatively, solar-hydrogen could be used also in appropriate burners, by using pure oxygen or air as oxidant substances, to produce water and a significant amount of thermal energy. The same fuel cells could be employed in the residential sector for cogenerative applications. Finally, solar-hydrogen could be used as new energy carrier in the transportation sector to supply the existing vehicles equipped 


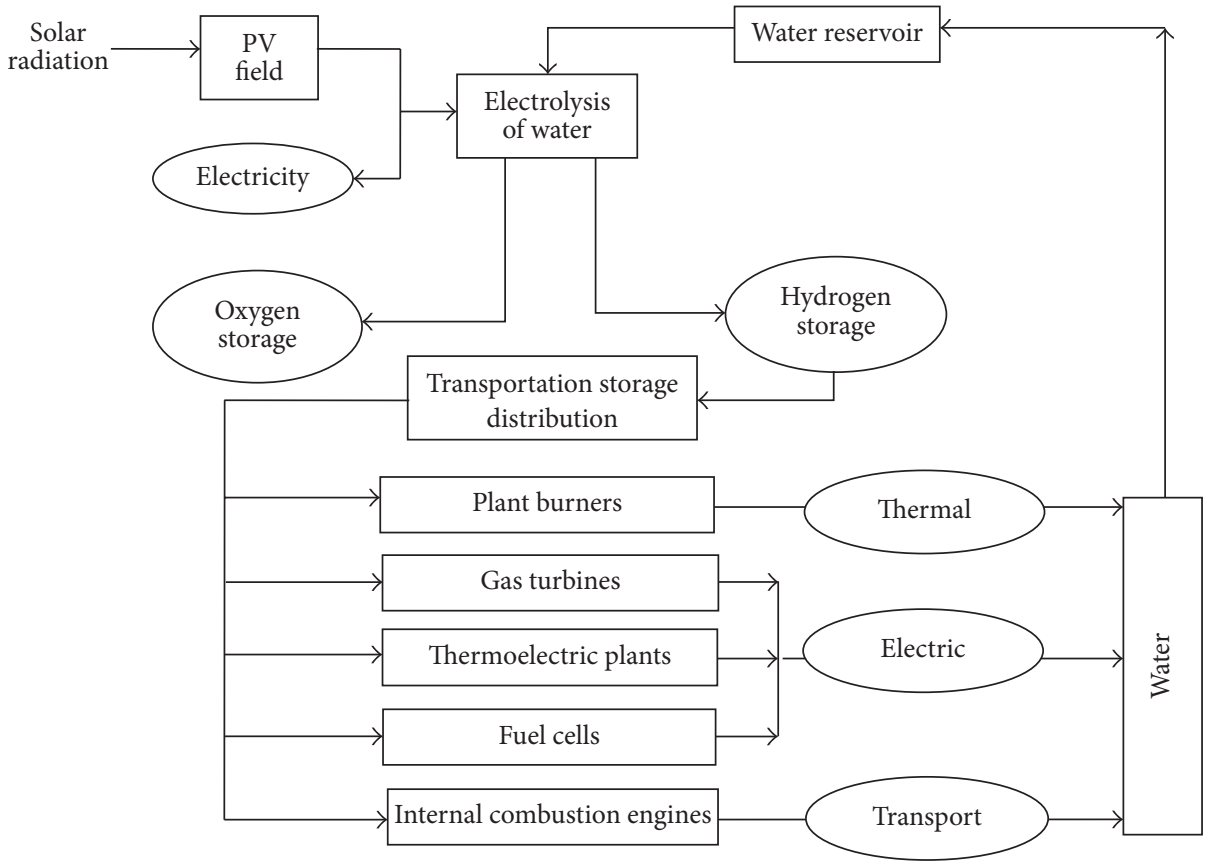

FIGURE 1: Possible scheme of exploitation of hydrogen produced by solar radiation.

with electric engines. The electrolysis process, beyond hydrogen, allows the production of oxygen; therefore a further advantage is linked to the absence of nitrogen oxides in the combustion products.

In the scheme of Figure 1, hydrogen primarily assumes the tasks of storing and conveying the solar radiation towards the final use. Consequently, it is appropriate to consider the hydrogen as an energy carrier, as well as the electricity. In Figure 2, a more detailed scheme of solar-hydrogen exploitation is reported, together with the correspondent energy fluxes and the efficiencies of the involved processes. Possible ways to exploit solar hydrogen at different temperature levels are reported. Low enthalpy heat could be employed in heat pumps for heating application in buildings.

\section{The Entropic and Environmental Indexes in Combustion Processes}

The evaluation of the total cost by (1) requires the analytical determination of the weight factor " $p$," defined in this paper as product between entropic and environmental indexes. The first measures the quality of the chemical reaction, the second quantifies the emitted pollutant substances, and both are normalized in function of the amount of heat released during the combustion.

The combustion reactions represent an open thermodynamic system in which the entropy variation is sum of two terms: the first intrinsic due to irreversibility (always positive) and the second extrinsic (positive or negative) linked to the heat exchange through the border of the thermodynamic system [27]. During a combustion reaction, the produced chemical work plays a determining role in order to evaluate the entropy change, the enthalpy of formation, and the Gibbs potential [28].

The latter considers the energy contained in the initial components in a rate of available energy $\Delta \widetilde{h}$ and in another rate of constrained (not available) energy that can be written as

$$
\Delta(T \widetilde{s}+\mu) \equiv \Delta\left(T \widetilde{s}^{*}\right)
$$

In (2), the term $\widetilde{s}^{*}$ indicates a fictitious parameter that considers both the total entropy per unit of molar mass $(\widetilde{s})$ and the intrinsic work of the reaction $(\mu)$.

By considering conservatively the gasoline/diesel fuel as $\mathrm{C}_{8} \mathrm{H}_{18}$ (isooctane), which represents the newest and cleaner member of the hydrocarbons family, and the coal as pure carbon, the combustion reactions of the considered fuels in their stoichiometric form can be written as

(i) hydrogen:

$$
\mathrm{H}_{2} \mathrm{O} \leftrightarrows \mathrm{H}_{2}+\frac{1}{2} \mathrm{O}_{2}
$$

(ii) coal (gaseous form):

$$
\mathrm{CO}_{2} \leftrightarrows \mathrm{C}+\mathrm{O}_{2}
$$

(iii) natural gas (methane):

$$
\mathrm{CO}_{2}+2 \mathrm{H}_{2} \mathrm{O} \leftrightarrows \mathrm{CH}_{4}+2 \mathrm{O}_{2}
$$

(iv) gasoline:

$$
8 \mathrm{CO}_{2}+9 \mathrm{H}_{2} \mathrm{O} \leftrightarrows \mathrm{C}_{8} \mathrm{H}_{18}+12.5 \mathrm{O}_{2}
$$




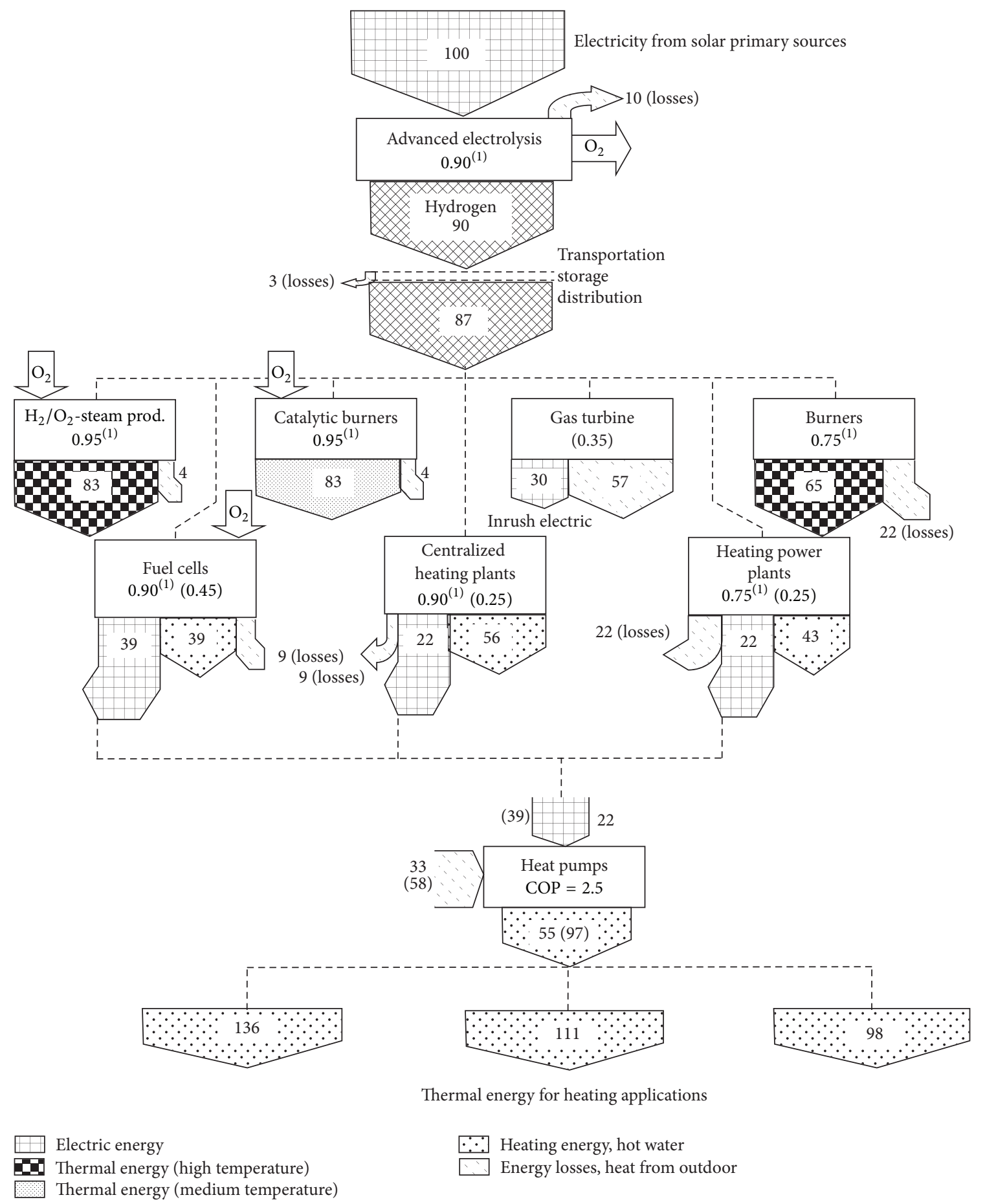

FIGURE 2: Hypothetic energy flux for the complete solar-hydrogen exploitation.

For each of these reactions, the values per mole unit of $\Delta \widetilde{h}$, $\Delta \widetilde{\mathfrak{s}}^{*}$, and $\Delta \widetilde{g}$ can be found in [29-31], at reference values of pressure and temperature equal, respectively, to $1 \mathrm{~atm}, 298 \mathrm{~K}$, and by fixing the reference entropy to the value calculated at a pressure of $1 \mathrm{~atm}$. The values are listed in Table 1 together with the molar specific heat at constant pressure and a reference absolute temperature $\langle T\rangle$, defined as the mean value between the ambient temperature $(298 \mathrm{~K})$ and the combustion temperature. The specific heat at constant pressure is reported per mole unit for dimensional homogeneity. 
TABLE 1: Some thermodynamic parameters of hydrogen, methane, coal, and gasoline/diesel evaluated during stoichiometric combustion.

\begin{tabular}{lccccc}
\hline Fuels & $\begin{array}{c}\Delta \widetilde{h} \\
(\mathrm{~J} / \mathrm{mole})\end{array}$ & $\begin{array}{c}\Delta \widetilde{s}^{*} \\
(\mathrm{~J} / \mathrm{mole} \cdot \mathrm{K})\end{array}$ & $\begin{array}{c}\Delta \widetilde{g} \\
(\mathrm{~J} / \mathrm{mole})\end{array}$ & $\begin{array}{c}\tilde{c}_{p} \\
(\mathrm{~J} / \mathrm{mole} \cdot \mathrm{K})\end{array}$ & $\begin{array}{c}\langle T\rangle \\
(\mathrm{K})\end{array}$ \\
\hline $\mathrm{H}_{2}$ & -251100 & 56.6 & -0.39 & 14.304 & 1451 \\
$\mathrm{C}$ & -394500 & 57.4 & -0.53 & 15.576 & 1285 \\
$\mathrm{CH}_{4}$ & -870500 & 90.9 & -1.05 & 35.840 & 1155 \\
$\mathrm{C}_{8} \mathrm{H}_{18}$ & -5486500 & 1644.5 & -11.69 & 254.790 & 2035 \\
\hline
\end{tabular}

TABLE 2: Entropic impact indexes evaluated for hydrogen, methane, coal, and gasoline/diesel supposing stoichiometric reaction combustions.

\begin{tabular}{lc}
\hline Fuels & $i_{j s}$ \\
\hline $\mathrm{H}_{2}$ & 0.672 \\
$\mathrm{C}$ & 0.813 \\
$\mathrm{CH}_{4}$ & 0.879 \\
$\mathrm{C}_{8} \mathrm{H}_{18}$ & 0.390 \\
\hline
\end{tabular}

For each fuel, the entropic degradation during the combustions reaction is calculated by the proposed dimensionless index:

$$
i_{j s}=\left(1-\left|\frac{\Delta \widetilde{s}^{*} \cdot\langle T\rangle}{\Delta \widetilde{h}}\right|\right) \quad(j=\mathrm{a} \longrightarrow \mathrm{d}),
$$

where $j$ indicates the considered fuel ( $\mathrm{a}=$ solar-hydrogen; $\mathrm{b}=$ coal; $\mathrm{c}=$ methane; $\mathrm{d}=$ gasoline/diesel); $\Delta \widetilde{s}^{*}$ is the specific molar entropic generation of the combustion process; $\Delta \widetilde{h}$ is the specific molar enthalpy of the chemical reaction, assuming a similar meaning to the lower heating power of the $j$ th fuel.

The dimensionless entropic index $i_{j s}$ varies from the maximum value of 1 , for the ideal combustion, where $\Delta \widetilde{s}^{*}=$ 0 , to the minimum value of 0 , for the extreme case of total energy degradation. In the latter case, the increment of the temperature $\Delta T$ due to combustion involves a total transformation of the thermal energy in technical work, required to eject the mass of the combustion products, with no advantage in terms of heat released from the combustion reaction. By using the values reported in Table 1 , the value concerning the entropic index obtained for each fuel is listed in Table 2.

Considering exclusively the combustion quality, methane and coal assume a better score than hydrogen and gasoline/diesel; therefore the degradation of the external environment is smaller than the latter fuels. The hydrogen score is greater only than gasoline/diesel, but at this step the environmental properties are not considered yet. In order to quantify the effects linked to the pollutants emitted during the combustion reactions, another index, which considers exclusively the environmental properties of each fuel, is required. The latter is evaluated by (8), in function of the thermophysical properties of the $j$ th fuel and of the $k$ th pollutant content produced during standard combustion:

$$
i_{j E}=\prod i_{j k}
$$

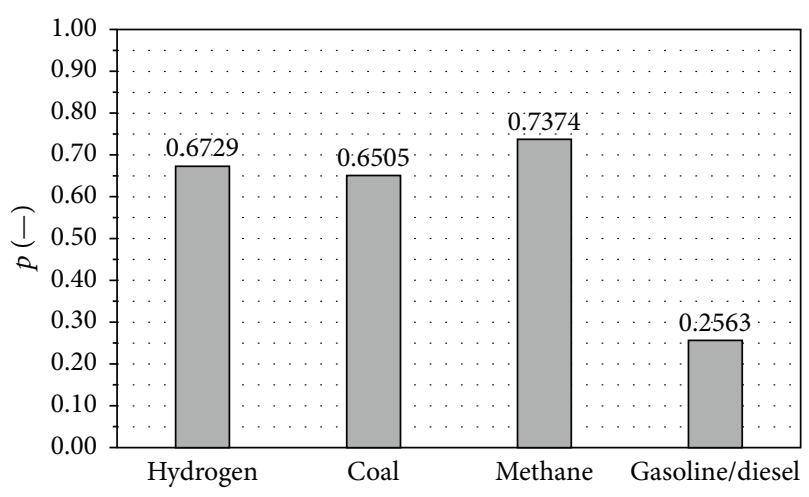

FIGURE 3: Weight factor for the evaluation of the external cost of the considered fuels.

The term $i_{j k}$ that compares in (8) is determined by means of the following equation [32]:

$$
i_{j k}=\left(1-\frac{m_{j k}}{|\Delta \widetilde{h}| /\left(\tilde{c}_{p} \cdot\langle T\rangle\right)}\right)_{k=1 \rightarrow 4},
$$

where $m_{j k}$ indicates the quantity of pollutant $(\mathrm{kg})$ released per kg of burned fuel; these parameters are grouped in Table 3 considering as main emitted substances $\mathrm{CO}_{2}, \mathrm{SO}_{2}, \mathrm{NO}_{x}$, and particulate dusts. Actually, the emission factors depend not only on the fuel thermodynamic characteristics, but also on the involved technology in the specific application sector. In simplified way, the values listed in Table 3 represent average emission coefficients indicated in [33] related to the European situation. For the gasoline, the emission factors have been modified taking into account also the pollutants produced by diesel combustion. The results obtained applying (9) are listed in Table 4, where the last column lists the environmental indexes determined by (8). The solar-hydrogen score becomes unitary because its exploitation with pure oxygen in fuel cells was supposed. Moreover, the water vapor was not considered as pollutant substance because the hypothesis of its complete recovery was adopted. Water vapor provided by fuel cells in urban areas, in fact, could be considered as a greenhouse gas.

In Figure 3 the weight factor " $p$ " to apply in (1) for the economic analysis, evaluated by means of the proposed indexes, is shown.

Despite the worse emission factors with respect to solar-hydrogen, the better combustion characteristics of the methane allow the obtainment of the best score. Conversely, the better environmental characteristics of solar-hydrogen compensate the gap with coal in terms of combustion quality. Among the investigated fuels, the gasoline/diesel presents the worst score for effect of the more penalized values obtained for the entropic and the environmental indexes.

\section{Evaluation of the Total Costs of the Fuels in Different Application Sectors}

The evaluation of global cost of the investigated fuels requires the knowledge of the correspondent market prices and the 
TABLE 3: Emission factor for the standard combustion per kg of burned fuel.

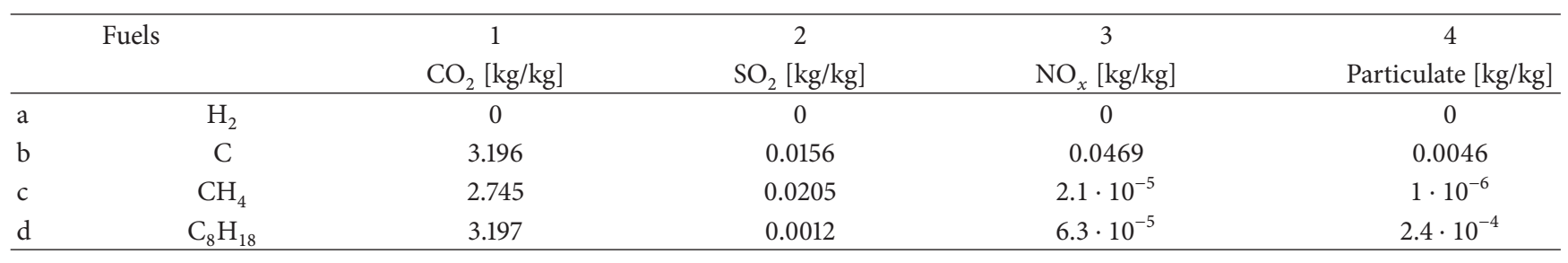

TABLE 4: Specific and global environmental indexes obtained for the investigated fuels.

\begin{tabular}{ccccccc}
\hline \multicolumn{2}{c}{ Fuels } & $i_{j 1}$ & $i_{j 2}$ & $i_{j 3}$ & $i_{j 4}$ & $i_{j E}$ \\
\hline $\mathrm{a}$ & $\mathrm{H}_{2}$ & 1.0000 & 1.0000 & 1.0000 & 1.0000 & $\mathbf{1}$ \\
$\mathrm{b}$ & $\mathrm{C}$ & 0.8034 & 0.9990 & 0.9971 & 0.9997 & $\mathbf{0 . 8 0 0 1}$ \\
$\mathrm{c}$ & $\mathrm{CH}_{4}$ & 0.8386 & 0.9999 & 0.9998 & 1.0000 & $\mathbf{0 . 8 3 8 5}$ \\
$\mathrm{d}$ & $\mathrm{C}_{8} \mathrm{H}_{18}$ & 0.6573 & 0.9998 & 0.9999 & 0.9999 & $\mathbf{0 . 6 5 7 2}$ \\
\hline
\end{tabular}

external costs. The market price of fossil fuels, in function of the application sector, can be found in different sources $[34,35]$. The cost of the hydrogen produced by photovoltaic technologies, by excluding other methods of solar energy exploitation, is subjected to numerous investigations [6]. It is mainly formed by the cost of the electricity provided by the photovoltaic field $\left(C_{\mathrm{PV}}\right)$ and by the cost due to the electrolysis process $\left(C_{\mathrm{El}}\right)$ [36]. In the last few years, the cost of the photovoltaic electricity was strongly reduced in relation to the recent incentive campaign adopted from different countries [37]. The cost of the electrolysis process is largely dependent on the cost of electricity, on the efficiencies, and on the capital costs of the systems. Because the system efficiency can be limitedly increased (current value is 78\%), the cost of the electrolysis process cannot be reduced by an efficiency increment as much as a significant reduction of the electricity price. For instance, by benefiting for forecourt systems of the same electricity prices for industries, the reduction of the cost of electrolysis process could be of $31 \%$ [38]. Moreover, if the hydrogen economy grows and the electrolyzer systems are mass produced, a substantial reduction in capital cost could be also achieved. Lastly, the cost related to the electrolysis process can be calculated in simplified way using the following relationship [36]:

$$
C_{\mathrm{El}}=\frac{I_{0}(A+M)}{\eta \cdot E_{\mathrm{el}}}=\frac{\text { Yearly global specific cost }}{\text { Yearly specific energy produced }},
$$

where $I_{0}$ is the investment cost sustained to acquire the electrolyzer, including installation cost $(€) ; A$ is the actualization factor, usually set equal to the amortized cost and by providing a useful life of the plant equal to 20 years; $M$ is the percentage factor concerning the annual cost of maintenance and management of the system, including the staff cost, set to $5 \% ; \eta$ is the electrolyzer efficiency in order to transform electric energy in chemical energy stored as hydrogen $\left(E_{\mathrm{H}_{2}}\right)$.

By supposing large-scale production, a global cost of about $6.67 € / \mathrm{kg}$ for solar-hydrogen has been determined exploiting the technology of plane PV [39]. The lower heating value for hydrogen is equal to $34.86 \mathrm{kWh} / \mathrm{kg}$; therefore a correspondent specific energy cost of $0.191 € / \mathrm{kWh}$ has been determined. In [40], with reference to the European power generation sector, in 2013 an average levelised cost of electricity ranging from $0.059 € / \mathrm{kWh}$ (coal) to $0.086 € / \mathrm{kWh}$ (combined power plant fired by methane) is reported. Consequently, without considering the additional costs related to the retransformation of hydrogen into electrical energy, the obtained value is itself more 2-4 times higher than the cost obtained through exploitation of conventional fossil fuels. The economic competitiveness of solar-hydrogen could increase with a consistent reduction of the investment costs, both for the part concerning the photovoltaic system, by adopting more efficient technologies, and for the part concerning the electrolysis process. Regarding the reduction of the costs related to the PV technology, a considerable improvement of the scenario has been investigated in [41], where a specific energy cost to $0.09 € / \mathrm{kWh}$ has been quantified by using concentrator PV fields, characterized by higher solar conversion efficiencies (37\%). In this way, this specific cost becomes close to other hydrogen production methods, such as gas reformation, wind, and nuclear electrolysis. The determined gap cost with traditional fossil fuels becomes less severe if the social and environmental costs associated with their use are considered [42]. The "hidden" costs of fossil fuels can be quantified by the parameter $E$ that compares in (1). These values, for each considered fossil fuel, have been obtained from [43] where a suitable analytical tool makes the external cost for different energy carrier available. This tool was developed starting from the data carried out for six big cities of emerging countries. The comparison between solarhydrogen and the considered fossil fuels, in different fields of use (residential, industrial, electrical, and transportation), is shown in the following figures by separating the normalized fuel price $\left(C \cdot \eta_{0} / \eta\right)$ from the normalized external cost $\left(E \cdot p_{0}\right.$. $\left.\eta_{0} / p \cdot \eta\right)$. The obtained values have been determined hypothesizing fuel cells technologies for the hydrogen exploitation, with the following values of the efficiency $\eta$ in function of the application sector:

(i) 0.8 for the residential and industrial sectors, by supposing to use fuel cells in cogenerative operation to produce heat and electricity at the same time;

(ii) 0.45 for the power generation and the transportation sectors, by supposing the employment of electric engines in the cars. 


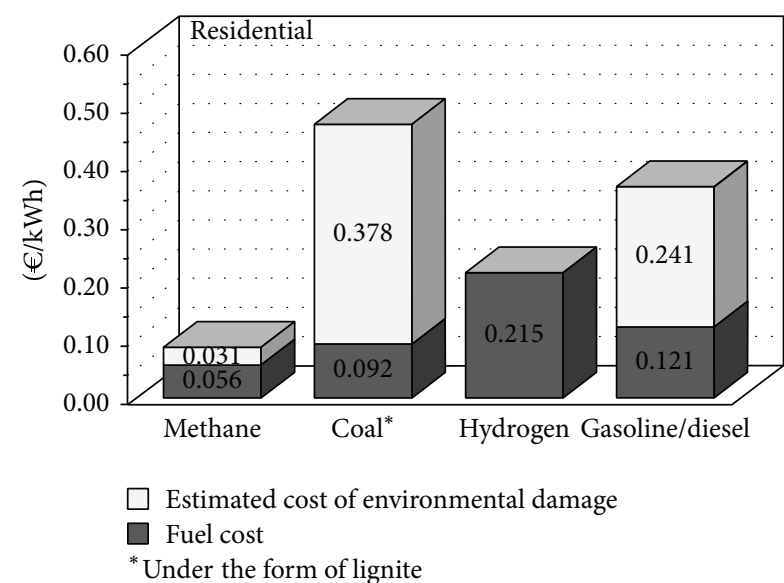

(a)

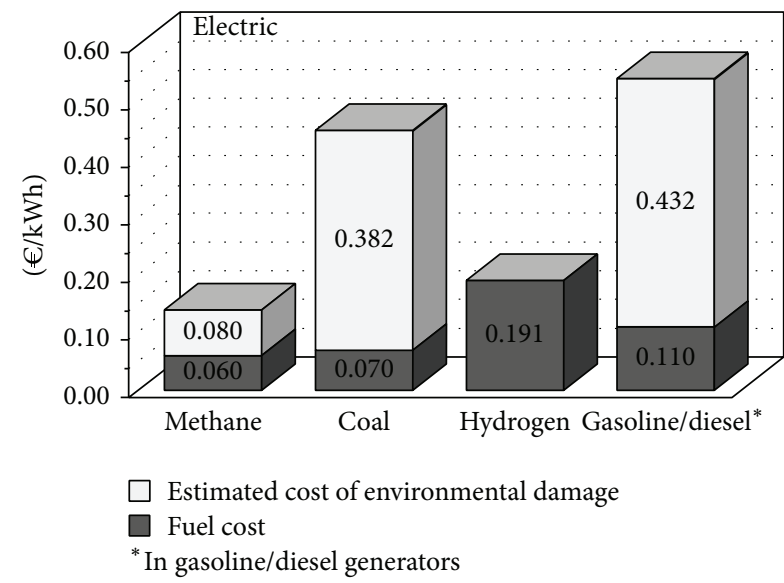

(c)

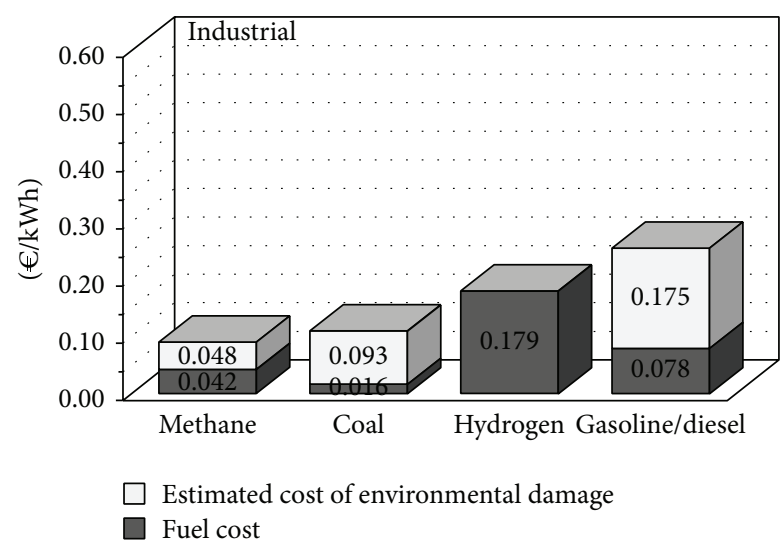

(b)

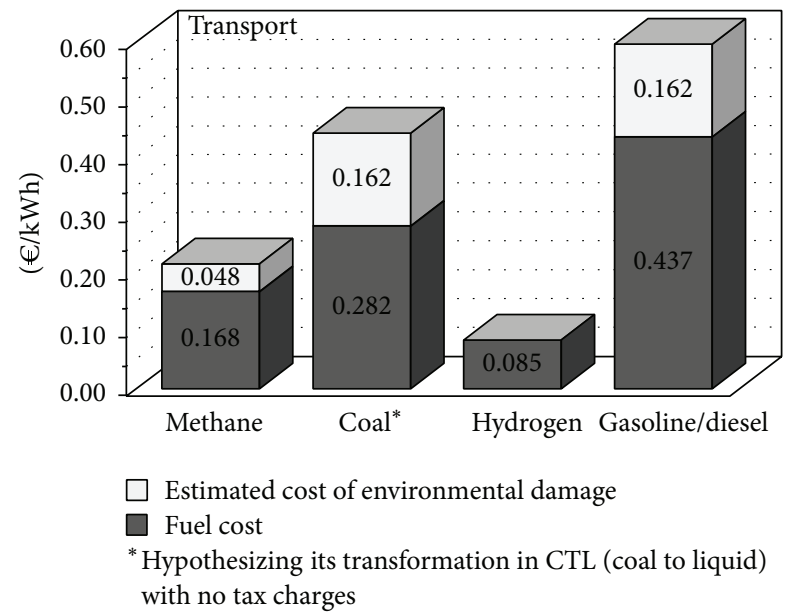

(d)

FIGURE 4: (a) Fuel prices and external costs in the residential sector. (b) Fuel prices and external costs in the industrial sector. (c) Fuel prices and external costs in the power generation sector. (d) Fuel prices and external costs in the transport sector.

Regarding the efficiency $\eta$ of traditional technologies supplied by fossil fuels, the adopted value is

(i) 0.9 for residential sector, hypothesizing hybrid boilers for the production of heat and electricity (equipped, e.g., with Stirling engines [44]);

(ii) 0.75 for industrial sector in cogenerative operations;

(iii) 0.45 for the power generation sector, resulting as average value between the efficiency of combined cycles and conventional Rankine cycles;

(iv) 0.20 for the transportation sector.

The analytical results of the economic analysis are plotted in Figures $4(\mathrm{a})-4(\mathrm{~d})$, in function of the application sector and for the considered fuels.

Currently, the real cost of solar-hydrogen becomes already profitable for the transportation sector, taking advantage from the better efficiency of the electric traction. Moreover, the absence of taxation costs makes the market price of solar-hydrogen lower than those of the fossil fuels. For the industrial sector, solar-hydrogen in fuel cells becomes profitable only if compared to technologies supplied by gasoline/diesel, because the lower market prices of methane and coal still compensate the external costs. A better situation has been detected for the power generation sector, where solarhydrogen is more attractive than coal and gasoline, while the methane technologies are still profitable. Despite the lower market prices, the position of coal and gasoline/diesel in the ranking is strongly penalized from the elevated external costs. Finally, in residential sector fuel cells supplied by solar-hydrogen present a better position compared to coal and gasoline/diesel technologies, but methane remains still profitable in relation to the improvement of the boiler technologies that limit the external costs.

\section{Conclusions}

The real costs of energy system supplied by solar-hydrogen and some fossil fuels have been determined. The real cost includes the "external" costs related to the final use of the fuels, considering air pollution and environmental damage. 
The investigated fuels present different thermodynamic characteristics and, usually, are employed in different devices characterized by dissimilar values of thermodynamic efficiency. In this paper, to obtain homogenized results that consider the mentioned aspects, a weight factor has been determined in order to assess an economic analysis based on the "real economy" approach. The weight factor was evaluated by means of a thermodynamic approach employed to quantify two quality indexes: an entropic index concerning the quality of the combustion reaction, and an environmental index to quantify the main emitted pollutant substances. Moreover, the proposed indexes have been normalized in function of the heat released during the combustion process. The thermodynamic approach described in this paper has allowed a direct comparison among four fuels usually employed as energy carriers: solar-hydrogen, methane, coal, and gasoline/diesel. Regarding the proposed weight factor, the results show a position of hydrogen secondary only to methane, which presents the better combination between combustion characteristics and emitted pollutants. From an economic point of view, considering four energy application sectors (residential, industrial, power generation, and transport), the real costs have highlighted that solar-hydrogen becomes already more attractive in the transportation sector, presenting the lowest value. In the industrial sector, the lower market prices of methane and coal make these fuels more attractive, since they compensate widely the external costs. Therefore, the position of solar-hydrogen will improve only with a large augment of the market price of fossil fuel in the next future, for effect of their inevitable depletion. The same evaluations can be done for the energy sector, where solar-hydrogen is already competitive than coal in relation to the large external costs of the latter. Nowadays, in the residential sector, solar-hydrogen is a good alternative for the replacement of old boilers supplied by gasoline/diesel or coal. The position of solar-hydrogen is still worse than methane, since the improvement and the diffusion of condensation boilers equipped with burner at low combustion temperatures have produced limited external costs. In reality, the evaluated real costs for solar-hydrogen become optimistic, since its market price is not suffered by tax charges. In the future, the replacement of the traditional fuels will cause an inevitable taxation also on the new energy carriers, including solar-hydrogen, to guarantee the financial revenue derived from fuel commerce. Therefore, the economic scenario above introduced will be surely different. However, the determined real cost gaps among the investigated fuels will become useful to evaluate an adequate taxation level for solar-hydrogen. On the other hand, the mass production of electrolyzer technologies, the reduction of the PV electricity costs, or the improvement of the PV technologies will determine a reduction of the solar-hydrogen cost that could compensate the tax charges.

In a short-term scenario, in absence of tax charge of solarhydrogen, its diffusion becomes already profitable than gasoline/diesel technologies in every application sector. Therefore, the obtained results show that an economical persuasion to exploit solar-hydrogen as new energy carrier in different application sectors could already exist.

\section{Nomenclature}

A: Actualization factor [-]

$\widetilde{c}:$ Molar specific heat $[\mathrm{J} / \mathrm{mole} \cdot \mathrm{K}]$

$C$ : Fuel market cost $[€]$

$E$ : External cost $[€]$

$\tilde{g}$ : Molar Gibbs energy [J/mole]

$\widetilde{h}$ : Molar enthalpy [J/mole]

I: Investment [€]

$i$ : Impact index [-]

$m$ : Pollutant emission factor $[\mathrm{g} / \mathrm{kg}]$

$M$ : Management and maintenance rate [-]

$p$ : Weight factor $[-]$

$P$ : Pressure $[\mathrm{Pa}]$

$\widetilde{s}: \quad$ Molar entropy $[\mathrm{J} / \mathrm{mole} \cdot \mathrm{K}]$

$S: \quad$ Real cost $[€]$

$T$ : Temperature $[\mathrm{K}]$.

Greek Symbols

$\eta$ : Efficiency [-]

$\mu$ : Apparent work [J/mole]

$\widetilde{v}$ : Molar volume $\left[\mathrm{m}^{3} / \mathrm{mole}\right]$.

\section{Subscripts and Superscripts}

$0: \quad$ At the year 0

el: Electricity

E: Environmental

El: Electrolyzer

$\mathrm{H}_{2}$ : Hydrogen

$j:$ Fuel type

$k$ : Pollutant type

$p$ : Constant pressure

PV: Photovoltaic

$o$ : Reference

$S$ : Combustion.

\section{Conflict of Interests}

The authors declare that there is no conflict of interests regarding the publication of this paper.

\section{References}

[1] I. Dincer and C. Acar, "A review on clean energy solutions for better sustainability," International Journal of Energy Research, vol. 39, no. 5, pp. 585-606, 2015.

[2] P. D. Lund, "Clean energy systems as mainstream energy options," International Journal of Energy Research, vol. 40, no. 1, pp. 4-12, 2016.

[3] N. Armaroli and V. Balzani, Energy for a Sustainable World: From the Oil Age to a Sun-Powered Future, John Wiley \& Sons, Hoboken, NJ, USA, 2010.

[4] G. Nicoletti, "Hydrogen as solar energy storage-technical and economical aspects," in Proceedings of the International Congress Hypothesis, Cassino, Italy, June 1995.

[5] J. R. White, "Comparing solar energy alternatives," International Journal of Energy Research, vol. 8, no. 1, pp. 39-52, 1984. 
[6] J. Turner, G. Sverdrup, M. K. Mann et al., "Renewable hydrogen production," International Journal of Energy Research, vol. 32, no. 5, pp. 379-407, 2008.

[7] J. Andrews and B. Shabani, "Re-envisioning the role of hydrogen in a sustainable energy economy," International Journal of Hydrogen Energy, vol. 37, no. 2, pp. 1184-1203, 2012.

[8] Gi. Nicoletti and Ge. Nicoletti, "L'idrogeno come opzione energetica sostenibile," in Proceedings of the 8th Italian Conference CIRIAF, Perugia, Italy, April 2010.

[9] J. M. Ogden, Alternative Fuels and Prosects-Overview, John Wiley \& Sons, Hoboken, NJ, USA, 2010.

[10] P. Kumar, K. Dutta, S. Das, and P. P. Kundu, "An overview of unsolved deficiencies of direct methanol fuel cell technology: factors and parameters affecting its widespread use," International Journal of Energy Research, vol. 38, no. 11, pp. 1367-1390, 2014.

[11] J.-Y. Hwang, S. Shi, X. Sun, Z. Zhang, and C. Wen, "Electric charge and hydrogen storage," International Journal of Energy Research, vol. 37, no. 7, pp. 741-745, 2013.

[12] K. Kendall, "Hydrogen and fuel cells in city transport," International Journal of Energy Research, vol. 40, no. 1, pp. 30-35, 2016.

[13] A. Züttel, "Hydrogen storage methods," Naturwissenschaften, vol. 91, no. 4, pp. 157-172, 2004.

[14] I. A. Gondal and M. H. Sahir, "Prospects of natural gas pipeline infrastructure in hydrogen transportation," International Journal of Energy Research, vol. 36, no. 15, pp. 1338-1345, 2012.

[15] S. Blanchette Jr., "A hydrogen economy and its impact on the world as we know it," Energy Policy, vol. 36, no. 2, pp. 522-530, 2008.

[16] L. I. González-Monroy and A. Córdoba, "Financial costs and environmental impact optimization of the energy supply systems," International Journal of Energy Research, vol. 26, no. 1, pp. 27-44, 2002.

[17] J. X. Weinert, L. Shaojun, J. M. Ogden, and M. Jianxin, "Hydrogen refueling station costs in Shanghai," International Journal of Hydrogen Energy, vol. 32, no. 16, pp. 4089-4100, 2007.

[18] M. W. Melaina, "Initiating hydrogen infrastructures: preliminary analysis of a sufficient number of initial hydrogen stations in the US," International Journal of Hydrogen Energy, vol. 28, no. 7, pp. 743-755, 2003.

[19] S. Prince-Richard, M. Whale, and N. Djilali, "A technoeconomic analysis of decentralized electrolytic hydrogen production for fuel cell vehicles," International Journal of Hydrogen Energy, vol. 30, no. 11, pp. 1159-1179, 2005.

[20] T. N. Veziroğlu and F. Barbir, "Economic comparison of hydrogen and fossil fuel systems," in Clean Utilization of Coal: Coal Structure and Reactivity, Cleaning and Environmental Aspects, Y. Yurum, Ed., vol. 370 of NATO ASI Series, pp. 295-313, Springer, Dordrecht, The Netherlands, 1992.

[21] G. Nicoletti and R. Arienti, "Aspetti Entropici dell'Impatto Ambientale da combustione," in Proceedings of the 4th Italian Conference "Analisi Ambientale in Italia", Milan, Italy, 1992.

[22] I. Dincer and M. A. Rosen, "Thermodynamic aspects of renewables and sustainable development," Renewable and Sustainable Energy Reviews, vol. 9, no. 2, pp. 169-189, 2005.

[23] N. Kousuke, T. Toshimi, and K. Shinichi, "Analysis of entropy generation and exergy loss during combustion," Proceedings of the Combustion Institute, vol. 29, no. 1, pp. 869-874, 2002.
[24] T. N. Veziroglu, "Economic comparison of solar hydrogen energy system with fossil fuel system," in Solar-WasserstoffVersorgung: Internationales Symposium, Zürich, Switzerland, November 1989.

[25] A. Fonseca, V. Sá, H. Bento, M. L. C. Tavares, G. Pinto, and L. A. C. N. Gomes, "Hydrogen distribution network optimization: a refinery case study, Journal of Cleaner Production, vol. 16, no. 16, pp. 1755-1763, 2008.

[26] I. Dincer and M. A. Rosen, "Sustainability aspects of hydrogen and fuel cell systems," Energy for Sustainable Development, vol. 15, no. 2, pp. 137-146, 2011.

[27] E. A. Guggenheim, Thermodynamics, North Holland, Amsterdam, The Netherlands, 5th edition, 1977.

[28] Hutte, Theoretische Grundlagen, W. Ernst \& Sohn, Berlin, Germany, 28th edition, 1985.

[29] L. Bornstein, Chemische Handbuch, vol. II/4, Auer, 6th edition, 1959.

[30] P. Chilton, Chemical Engineering Handbook, McGraw-Hill, New York, NY, USA, 1973.

[31] R. C. Weast, Handbook of Chemistry and Physics, CRC Press, New York, NY, USA, 1977.

[32] G. Nicoletti, N. Arcuri, G. Nicoletti, and R. Bruno, "A technical and environmental comparison between hydrogen and some fossil fuels," Energy Conversion and Management, vol. 89, pp. 205-213, 2015.

[33] EEA, "EMEP/EEA air pollutant emission inventory guidebook 2013: technical guidance to prepare national emission inventories," European Environmental Agency Technical Report 12/2013, European Environment Agency, Copenhagen, Denmark, 2013.

[34] http://www.fuel-prices-europe.info/.

[35] VVAA, DECC Fossil Fuel Price Projections-Gov.uk, Department of Energy and Climate Change of UK, 2014.

[36] D. Coiante, "La produzione fotovoltaica dell'idrogeno," Notiziario ENEA “Energia ed Innovazione”, no. 11-12, pp. 24-41, 1990.

[37] VVAA, “Global Market Outlook for Photovoltaics 2014-2018," EPIA-European Photovoltaic Industry Association, http:// www.cleanenergybusinesscouncil.com/site/resources/files/reports/ EPIA_Global_Market_Outlook_for_Photovoltaics_2014-2018_-_ Medium_Res.pdf.

[38] VVAA, Technology Brief: Analysis of Current-Day Commercial Electrolyzers, NREL-National Renewable Energy Laboratory-Department of Energy, Washington, DC, USA, 2004.

[39] P. E. Dodds and W. McDowall, "A review of hydrogen production technologies for energy system models," UKSHEC Working Paper 6, UCL Energy Institute, University College London, London, UK, 2012.

[40] C. Kost, J. N. Mayer, J. Thomsen et al., "Levelized cost of electricity renewable energy technologies," Report, Fraunhofer Institute for Solar Energy Systems ISE, Freiburg, Germany, 2013, http://www.ise.fraunhofer.de/en/publications/veroeffentlichungen-pdf-dateien-en/studien-und-konzeptpapiere/study-levelized-cost-of-electricity-renewable-energies.pdf.

[41] J. R. Thomson, R. D. McConnell, and M. Mosleh, "Cost analysis of a concentrator photovoltaic hydrogen production system," in Proceedings of the International Conference on Solar Concentrators for the Generation of Electricity or Hydrogen, Scottsdale, Ariz, USA, May 2005. 
[42] National Research Council, Hidden Costs of Energy: Unpriced Consequences of Energy Production and Use, The National Academies Press, Washington, DC, USA, 2010.

[43] K. Lvovsky, G. Hughes, D. Maddison, B. Ostro, and D. Pearce, "Environmental costs of fossil fuels: a rapid assessment method with application to six cities," Environment Department Paper, Report for the World Bank, 2010.

[44] M. De Paepe, P. D’Herdt, and D. Mertens, "Micro-CHP systems for residential applications," Energy Conversion and Management, vol. 47, no. 18-19, pp. 3435-3446, 2006. 


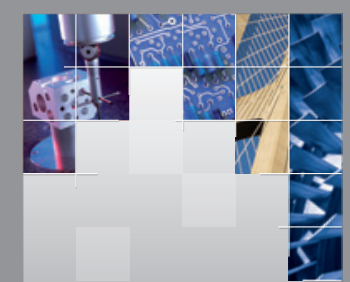

\section{Enfincering}
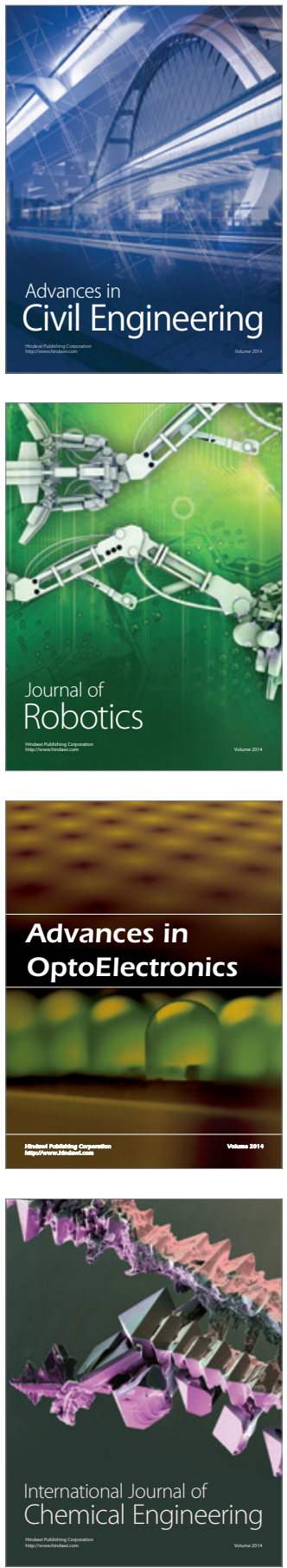

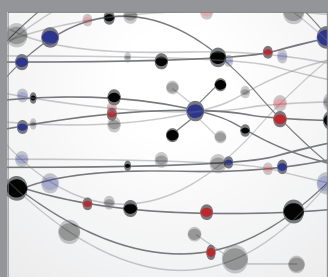

The Scientific World Journal

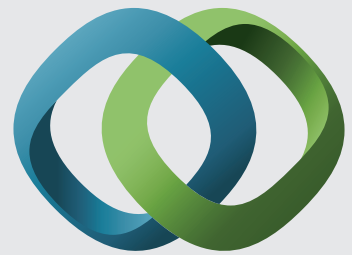

\section{Hindawi}

Submit your manuscripts at

http://www.hindawi.com
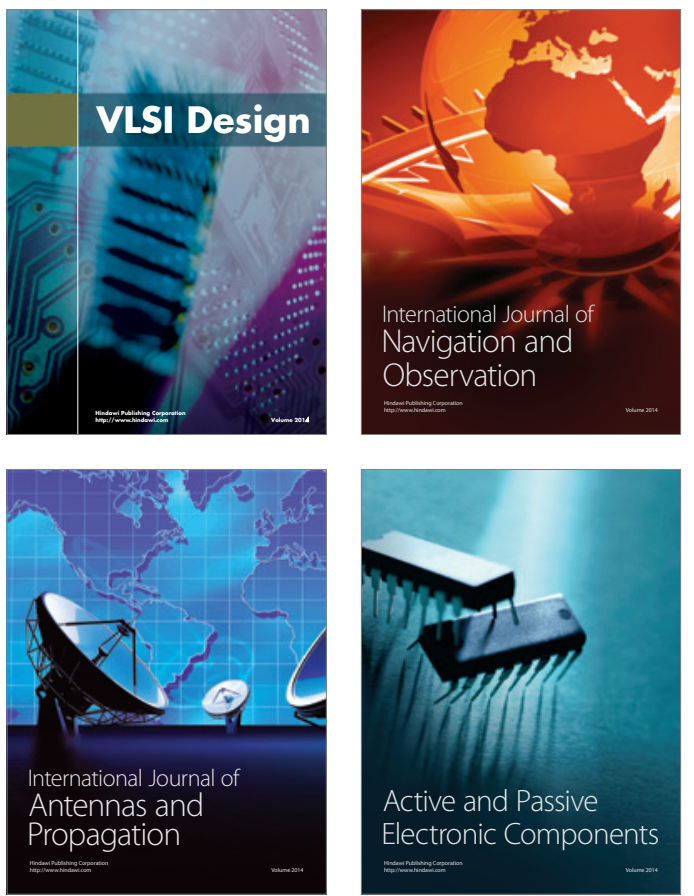
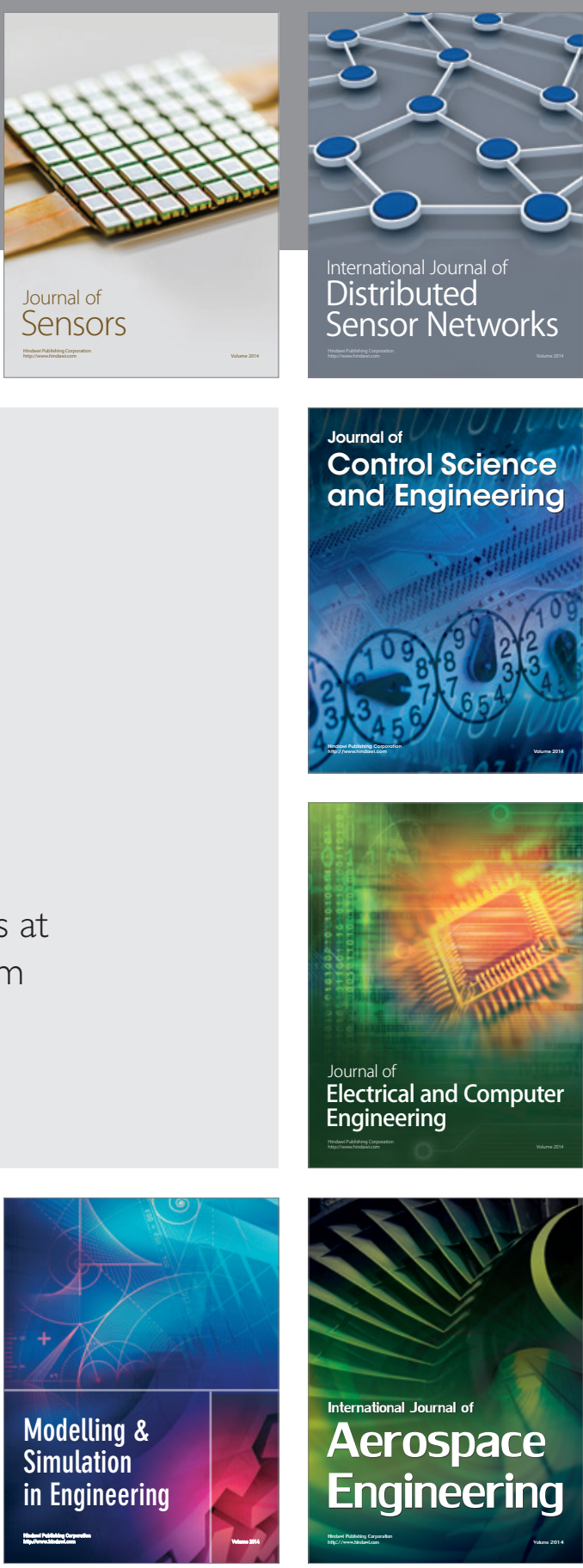

International Journal of

Distributed

Sensor Networks

Journal of

Control Science

and Engineering
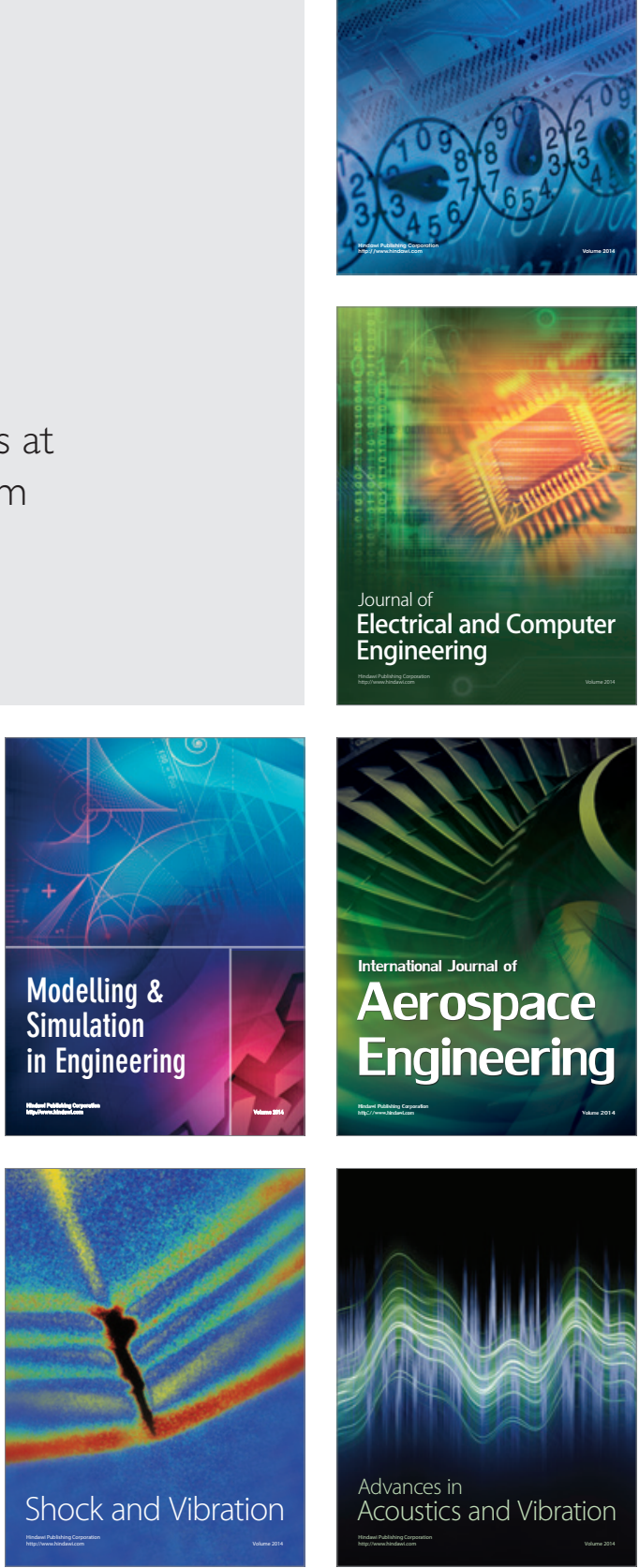